\title{
Rejanellus, a new genus of Thomisidae (Araneae, Stephanopinae)
}

\author{
Arno Antonio Lise \\ Laboratório de Aracnologia, Faculdade de Biociências, Pontifícia Universidade Católica do Rio Grande do Sul, Av. Ipiranga, 6681,
} 90619-900 Porto Alegre, RS, Brasil. (lisearno@pucrs.br)

\begin{abstract}
A new genus, Rejanellus, type species Onocolus venustus Bryant, 1940, is established for four species of spiders of the subfamily Stephanopinae from Cuba and Haiti. The presence of dorsal tubercles on the male carapace is a possible synapomorphy for the genus. The four known species by now Onocolus venustus Bryant, 1948, O. pallescens Bryant, 1940, O. granulata [sic] Bryant, 1940 and Epicadus mutchleri Petrunkevitch, 1930 are transferred to the new genus. All species are redescribed and illustrated.
\end{abstract}

KEYWORDS. Rejanellus, Thomisidae, Stephanopinae, Neotropical, systematics.

RESUMO. Rejanellus, um novo gênero de Thomisidae (Araneae, Stephanopinae). Um novo gênero, Rejanellus, tendo como espécie-tipo Onocolus venustus Bryant, 1940, é estabelecido para quatro espécies da subfamília Stephanopinae, de Cuba e Haiti. A presença de tubérculos dorsais na carapaça do macho é uma possível sinapormorfia para o gênero. As quatro espécies conhecidas até o momento Onocolus venustus Bryant, 1948, O. pallescens Bryant, 1940, O. granulata [sic] Bryant, 1940 e Epicadus mutchleri Petrunkevitch, 1930 são transferidas para o novo gênero. Todas as espécies são redescritas e ilustradas.

PALAVRAS-CHAVE. Rejanellus, Thomisidae, Stephanopinae, Região Neotropical, sistemática.

The subfamily Stephanopinae was proposed by O. PiCKARD-CAMBrige in 1871. The representatives of this subfamily can be easily recognizable by having $2-4$ teeth on the promargin of chelicerae fang furrow and 1-3 on the retromargin.

Lise (1981), revising the genus Onocolus Simon, 1895 detected that some species included in this genus were not congeneric. Thus, Onocolus pallescens Bryant, 1940, Onocolus granulata [sic] Bryant, 1940 and Onocolus venustus Bryan, 1948 are now transferred to the new genus. Epicadus mutchleri Petrunkevitch, 1930 is also transferred to this new genus. Eleven genera are now reported for neotropical Stephanopinae.

\section{MATERIAL AND METHODS}

The material examined belongs to the Museum of Comparative Zoology (MCZ), Harvard University, Cambridge, and American Museum of Natural History $(\mathrm{AMNH})$, New York. The measurements are in millimeters. Both carapace and total length were took from the anterior margin of AME. The abbreviations related to eyes diameter, interdistances and median ocular quadrangle are those routinely used in spider descriptions and are: AME, ALE, PME, PLA, AME-AME, AME-ALE, PMEPME, PME-PLE, MOQ. The chaetotaxy follows PLATNICK $\&$ SHADAB (1975).

\section{Rejanellus new genus}

Epicadus SIMON, 1895:1052 (partim)

Onocolus SIMON, 1895:1053 (partim)

Type species: Onocolus venustus Bryant, 1948.

Etimology. The generic name honors Rejane Rosa, the drawer of the Museu de Ciências Naturais, Fundação
Zoobotânica do Rio Grande do Sul who, for long time, has been giving her contribution to the illustration of scientific papers. The generic name Rejanellus is masculine.

Diagnosis. The males of this genus can be distinguished from those of the other neotropical Stephanopinae by the shape of the carapace that is higher than the ones of the other genera and has blunt median dorsal tubercles (figs. 3, 28, 37, 46). The cephalic region and the median longitudinal portion of the carapace are higher than the rest of the carapace and have a groove, on each side of the median longitudinal area, that extends till the level of leg III. Clypeus high and proclivous, normally festooned, with, without or at least not detected paired macrosetae on the inferior margin. The cymbium is high and the embolus short, arising on the middle prolateral margin of the tegulum. The females have a lower and less granular carapace, without the median dorsal tubercles. Lateral eyes on tubercles apart to each other, the ALE tubercle larger than the PLE. Legs with strong setae, tarsus without claw tufts, with one single tooth or no tooth at all. The abdomen has neither laterals nor posterior well-developed tubercles, as occurs on the representatives of Onocolus and Epicadus, and some other Stephanopinae, except on the female of $R$. pallescens and the male of $R$. venustus. The anterior and lateral margins of the abdomen are normally festooned.

Description. Medium to small spiders. Total length of females 5.75-8.00, males 2.50-3.30. Carapace pearshaped, narrowed on the cephalic region with almost parallel sides, somewhat longer than wide, widest at level of coxa III, lower on females, in these, higher at level of coxa III. On males, higher at level of median dorsal tubercles (hump). Carapace densely granular with blunt median dorsal tubercles in males and a lateral serrated 

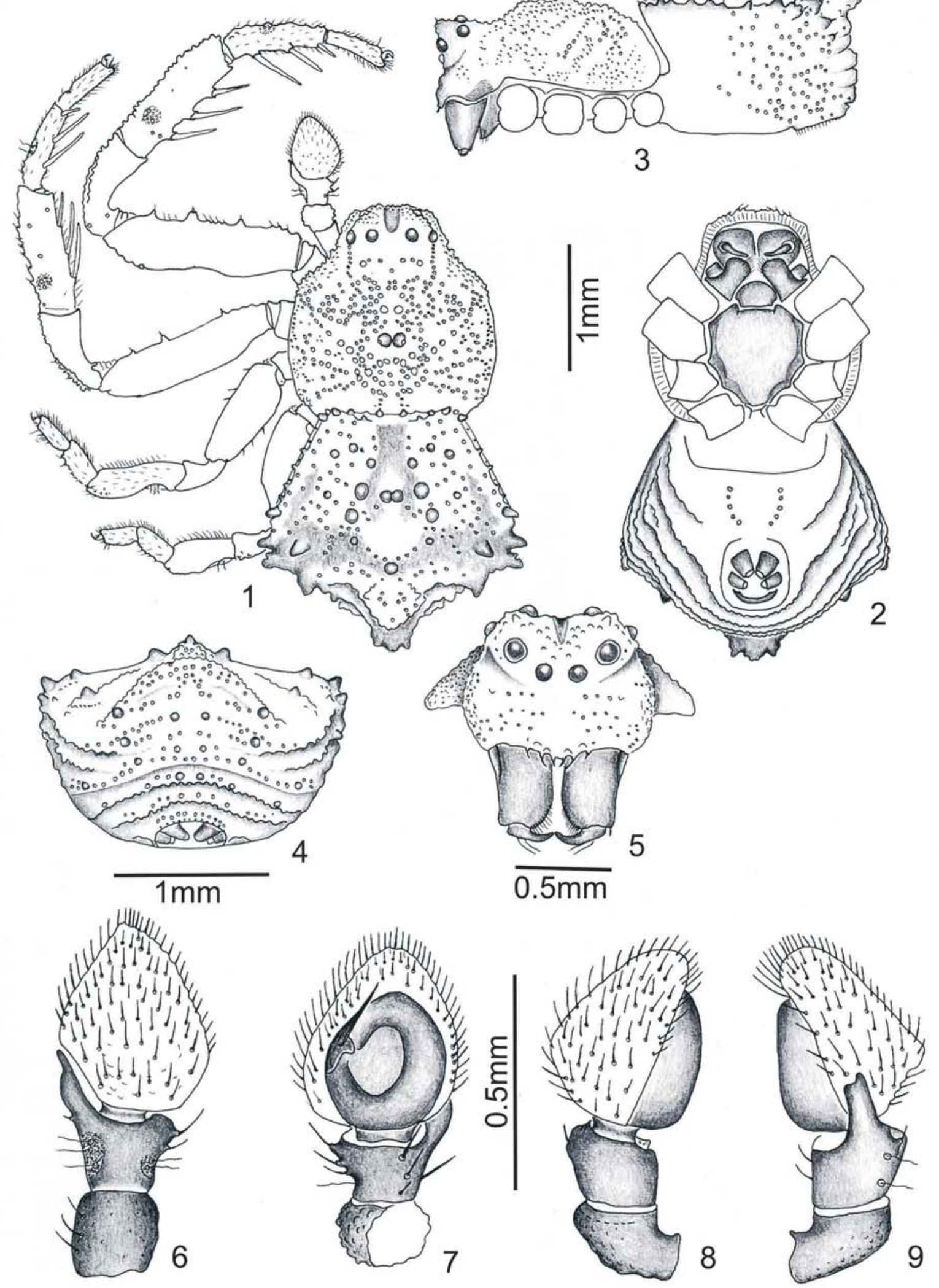

Figs.1- 9. Rejanellus venustus (Bryant, 1948), male holotype: 1, dorsal; 2, ventral; 3, lateral; 4, abdomen, posterior view; 5, carapace and chelicerae, frontal; 6-9, palpus: 6 , dorsal; 7 , ventral; 8 , prolateral; 9 , retrolateral. 
prominence on each side, at level of coxa I, lower and less granular without tubercles in females. The granules and in tubercles normally do not have either hairs or chaetae. Anterior row of eyes recurved, posterior straight or almost so. AME and PME eyes are the smallest. ALE are the biggest. AME apart from each other and from the ALE by roughly one diameter of AME. PME separated from each other by roughly three diameters of AME and from the PLE by one diameter. MOQ wider in back than in front on both, dorsal and frontal views. Chelicerae small, vertical, with two or three teeth on both margins of fang furrow, except on $R$. granulatus on which it was impossible to see teeth. Clypeus proclivous with four or six tubercles bearing setae. Labium short, normally somewhat wider than long. Sternum scutiform, slightly invaginate on anterior margin, lateral margins carved. Leg formula 1234, except in $R$. granulatus (1243). Leg spination: I and II - femur with ventral and dorsal tubercles bearing chaetae; tibia and metatarsus with three pairs of strong ventral spines. Patellae, tibiae and metatarsi of all legs with one dorsal and two dorsolateral longitudinal keels (fig. 63). Each side of dorsal and dorsolateral keels with excavations in which rest groups of short and long trichobothria in a circular botrium (figs. 69, 70) and feathery chaetae, these arising from a conic longitudinal grooved base (fig. 68). Along the dorsolateral and dorsal keels there are tubercles bearing large strong chaetae (fig. 64). On dorsal and lateral surfaces, the chaetae are arranged in almost parallel longitudinal rows (fig. 63). Tarsal organ capsulate (fig. 66).

Male palpus with patella and tibia granular and tuberculous with excavations on dorsal, prolateral and retrolateral faces. Excavations with groups of trichobothria. Retrolateral tibial apophysis of palpus simple, whose shape and length are diagnostic for each species. Cymbium higher on $R$. venustus, setose. Tegulum circular, moderately convex. Embolus style-shaped, short, apical. Ejaculatory duct simple, surrounding the ventral margin of tegulum. Epigynum forming a weakly sclerotized plate with different shapes. Copulatory openings inconspicuous, internally with two spherical or oval spermathecae with curved fertilization ducts, emerging from the base of posterior spermatheca (figs. 15-17, 23-25, 60-62).

Abdomen pentagonal, without posterior lateral and posterior median tubercles, except on the female of $R$. pallescens and male of $R$. venustus that have a posterior median tubercle well-developed. Tegument covered with tubercles of different sizes and granules, these normally devoid of both, hairs and chaetae.

Coments. The closest genera of Rejanellus gen. nov. are Tobias Simon, 1895, Epicadus Simon, 1895 and Epicadinus Simon, 1895. They can be separated from Rejanellus by the absence of the dorsal tubercles on the carapace and by having strong tubercles on the posterior end of the abdomen.

\section{Rejanelus venustus (Bryant, 1948) comb. nov.} (Figs. 1-17, 63-70)

Onocolus venustus BRYANT, 1948:416, figs.101-104, male holotype, Cordillera Central, Loma Runcilla Montains, Dominican Republic, IV.1938, Darlington col.; female allotype, Port-au-Prince, (Crew), Haiti, Banks col. Paratypes: female, San Domingo, (no collecting date), Banks col.; male and female, Haiti, hills near Port-au-Prince, X.1934, Darlington col.; male, Cordillera Central, Loma Viega, south of Constanza, Dominican Republic, 28.VIII.1938, Darlington col.; 3 males, 1 female (immature), Cordillera Central, Loma Runcilla Mountains, Dominican Republic, VI.1938, Darlington col., all in MCZ (examined). RoEWER, 1954:758.

Diagnosis. The male retrolateral tibial apophysis is similar to the one of $R$. granulatus but differs by being shorter and narrower on the apex. Embolus almost straight. Also differs from it and from the males of the other species by the acuminate dorsal surface of cymbium (fig. 9). The females can be distinguished from those of other species by the shape of the abdomen and epigynum (figs. 10, 14, 15-17).

Male: total length 3.30. Carapace 1.70 long, 1.62 wide, 0.75 height. Fulvous, strongly granulated and tuberculated, tubercles blackish. Carapace with a central tetra-tuberculated hump. Chelicerae 0.37 long, 0.27 wide, chestnut brown; half basal anterior face microgranular, remainig smooth. Sternum 0.77 long, 0.75 wide, anterior and lateral margins jagged, top truncated, convex, microgranular, brown. Endites 0.42 long, 0.20 wide, same color as sternum. Labium 0.22 long, 0.30 wide, brown. Clypeus 0.32 high, proclivous, concave, protruded on the center of margin, dark yellow, shadowed of brown.

Eye diameters and eye interdistances: AME 0.08, ALE 0.12, PME 0.12, PLE 0.08, AME-AME 0.06, AMEALE 0.06, PME-PME 0.21, PME-PLE 0.08. MOQ 0.25 long, dorsal view, 0.38 frontal view, anterior width 0.25 , posterior 0.38 . Anterior row recurved, posterior straight.

Legs: formula 1234, brown with yellow areas irregularly distributed. Tubercles and granules whitish. I, femur with 1.1.1 prolateral tubercles, the median larger, the other legs microgranulated. Patella, on transversal section, subretangular with a keel of granules on each side that join in the apex and another one, central. Tibia with 2.2.2 long ventral spines, all faces granular; on the middle of the basal third there is a prolateral excavation with trichobothria. Metatarsus with 2.2.2 ventral spines, shorter than the ones of tibia, with a dorsal excavation with trichobothria, on the basal third. Tarsus dilated on top, claws toothless. All articles microgranular. II. Femur as in I but the tubercles shorter, the other articles as in I. III and IV: femur smooth, patella granular, mainly on dorsal face. Tibia and metatarsus granular, both with a dorsal excavation on the basal third with trichobothria. Tarsus as in I.

Measurements. Leg I: femur 1.55, patella 0.80, tibia 1.05 , metatarsus 0.80 , tarsus 0.50 , total 4.70 ; II: $1.40 / 0.75 /$ 0.97/0.67/0.50/4.29; III: 0.87/0.74/0.67/0.32/0.30/2.63; IV: 0.90/0.30/0.52/0.30/0.30/2.32.

Palpus: same color of legs, dorsum of cymbium lighter, whitish yellow, very high. Tibial retrolateral apophysis as in figs. 6-9. Tibia with one retrolateral and one prolateral excavation with trichobothria. Embolus short, straight (fig. 7).

Abdomen pentagonal, 1.87 long, 2.12 wide, 1.00 high, whitish, spotted of black. Posterior third with a black V-shaped transversal band with the vertex turned backwards and another one, similar in shape, on the 

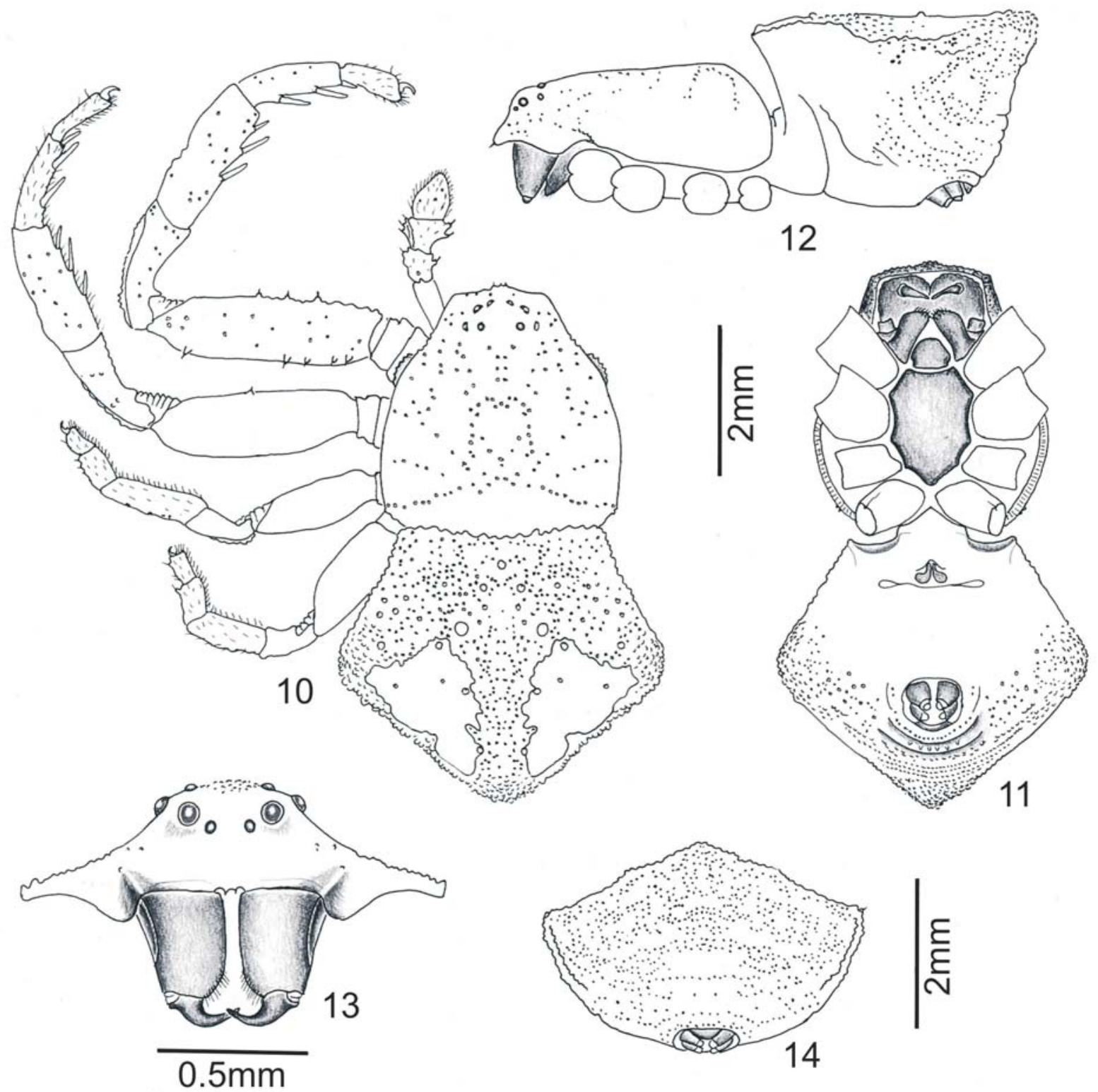

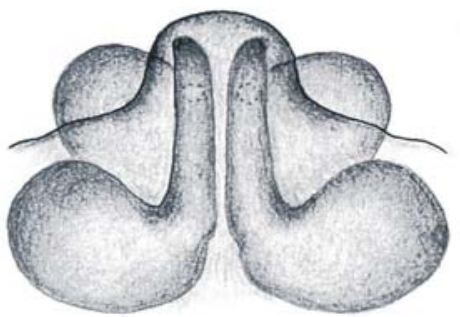

15

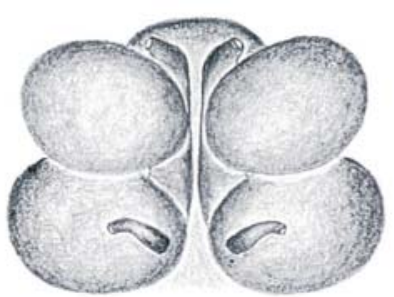

16
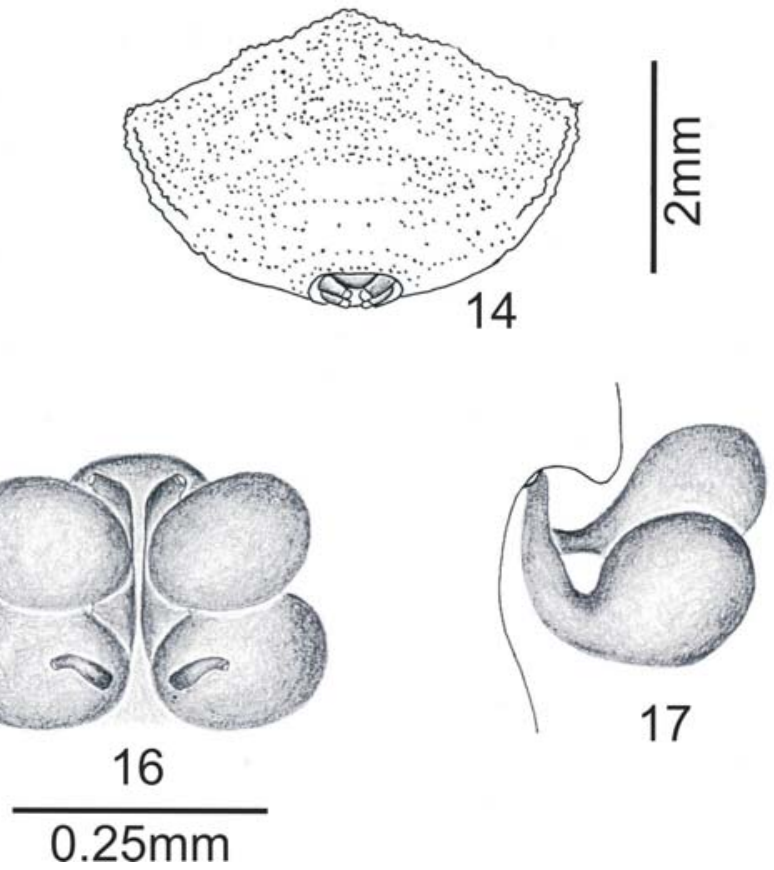

Figs.10-17. Rejanellus venustus (Bryant, 1948), female: 10, dorsal; 11, ventral; 12, lateral; 13, carapace and chelicerae, frontal; 14, abdomen, posterior view; 15-17 epigynum: 15, ventral; 16, dorsal; 17, lateral. 
dorsum of posterior tubercle. Posterior lateral and posterior angles tuberculated (fig.1). Dorsum and laterals densely covered with granules and some blunt tubercles. Venter whitish yellow with five pairs of circular depressions. Spinnerets yellow encircled by a chitinous half-ring, open in front.

Female: total length 6.25. Carapace 2.67 long, 2.62 wide, 0.50 height; gold-yellow, flat, higher on the posterior region. Dorsum with sparse white granules, the posterior ones arranged on three radial furrows, the remaining smooth. Chelicerae 0.67 long, 0.50 wide, bright yellow with three teeth on the promargin of fang groove and two on the retromargin; anterior face without bristles or tubercles. Sternum 1.20 long, 0.95 wide, light yellow, anterior and lateral margins jagged, moderately convex, tip rhomboid, ending between coxae IV. Endites 0.70 long, 0.33 wide, yellowish, convergent, tip rounded and scopulated. Labium 0.45 long, 0.42 wide, yellow. Clypeus 0.37 high, strongly proclivous, protruded on center, with four chaetae on the margin.

Eye diameter and eye interdistances: AME 0.08, ALE 0.17, PME 0.01, PLE 0.12, AME-AME 0.12, AMEALE 0.06, PME-PME 0.28,0ME-PLE 0.10. MOQ 0.41 long, dorsal view, 0.31 long, frontal view, anterior width 0.25 , posterior 0.47 .

Legs: formula 1234. I and II yellow, femur with prolateral, proventral and prodorsal tubercles, the last two disposed on marginal lines. Patella with three dorsal keels, densely granular and tuberculous on the dorsal and prolateral faces. Tibia and metatarsus with 2-2-2 ventral spines. Tarsus, claw tuffs formed by simple hairs, claw with one single tooth. III and IV same color of I and II but without both, tubercles on femur and ventral spines on tibia and metatarsus, other characters as in male.

Measurements. Leg I: femur 2.67, patella 1.37, tibia 1.70 , metatarsus 1.25 , tarsus 0.70 , total 7.64 ; II: $2.45 / 1.37 /$ 1.62/1.12/0.70/7.26; III: 1.37/0.75/1.05/0.50/0.73/4.04/IV: 1.74/0.67/0.87/0.50/0.32/3.83.

Palpus: light yellow, patella and tibia subtriangular, tibia with a dorsal excavation from which arise trichobothria. Prolateral face also with some basal trichobothria.

Abdomen pentagonal as on male, 3.75 long, 4.00 wide, 3.00 height. Dorsum flat, granular and tuberculous, milky white with a large dark brown reticulated spot on each side and another on the dorsum of posterior median tubercle. Laterals as dorsum, venter light yellow. Margins backward to lateral angles reborded with granules and tubercles. Posterior tubercle also tuberculous and granular. 15-17).

Epigynum and spermatecae light chestnut (figs.

Geographic distribution: Loma Runcilla Montains, and Loma Viega, south of Constanza, Cordillera Central, Dominican Republic; Port-au-Prince (Crew), Haiti.

Material examined: only the typical series.

Intraspecific variations ( 3 males): carapace could be yellow with the lines determined by the tubercles and granules fulvous or dark yellow with the lines brown to dark brown, almost black. One male has the abdominal tubercles black with fulvous apex. Another one is almost black spotted with white with two transversal white bands; the tubercles of dorsum are black with the apex milky white. The third specimen has white dorsum shadowed of dusky. This has two marginal white bands, which extend from the anterior lateral angles to the lateral tubercles.

\section{Rejanellus pallescens (Bryant, 1940) comb. nov. (Figs. 18-34)}

Onocolus pallescens BRYANT, 1940:411, fig.195, female holotype, original designation, from Pico Turquino, Cuba, VI.1936, P. J. Darlington col., in MCZ, examined; male alotype, here designated, from Hills near Port-au-Prince, Haiti, 2.X.1934,

P. J. Darlington col., in MCZ (examined), RoEwer, 1954:757.

Diagnosis. The carapace devoid of bristles, the posterior tubercle of the abdomen (fig. 18) and the shape of the posterior margin of the epigynum are diagnostic for the female. The shape of the retrolateral tibial apophysis of palpus and the smaller convexity of cymbium are for the male (fig. 25).

Female: total length 8.00. Carapace: 3.50 long, 3.40 wide, 1.50 high. Light yellow, with milky white tubercles (fig. 18). Dorsum slightly convex, tegument slightly sclerotinized, with few chaetae. Anterior portion of cephalic region narrow with almost parallel sides. Posterior declivity of carapace almost vertical and rounded. Chelicerae, same color of carapace, 0.82 long, 0.65 wide. Promargin of the fang furrow with three teeth, the medium larger, retromargin with two. Sternum scutiform, yellow, 1.70 long, 1.12 wide; excavated in front, rounded at the apex, convex, moderately hirsute (fig. 19). Endites 1.00 long, 0.45 wide, yellow, convergent, rounded at the tip with a promarginal scopula. Labium $0.55 \mathrm{long}$, 0.52 wide, yellow. Clypeus 0.40 high, strongly proclivous, protrusive at the middle with tubercles from each one arises one small bristle.

Eye diameters and eye interdistances: AME 0.10, ALE 0.17, PME 0.12, PLE 0.12, AMA-AME 0.12, AMAALE 0.10, PME-PME 0.35, PME-PLE 0.10. MOQ length, frontal view 0.50 , dorsal view 0.37 , anterior wide 0.32 , posterior wide 0.60 .

Legs: formula 1234. Leg I yellow, femur with proventral and prodorsal setiferous tubercles, these shorter and less numerous than the ventral ones; tegument microgranulose. Dorsum of patella tuberculous and granular with three keels. Tibia with 2.2.2 ventral spines, prolateral face excavated at the basal third, from where arise four trichobothria; dorsal surface with three keels, the lateral ones more conspicuous and an excavation from where arise two trichobothria. Metatarsus with 2.2.2 ventral spines; dorsal surface with one excavation with three trichobothria. Tarsus short, more dilated at the top, tarsal tuff not conspicuous, claws with one single basal tooth. Leg II as I but with tubercles only on the prolateral face of femur, less conspicuous and abundant. Legs III and IV, femur not tuberculous; patella with three keels on the dorsal face. Dorsum of tibia carbonated with an excavation bearing five trichobothria. 

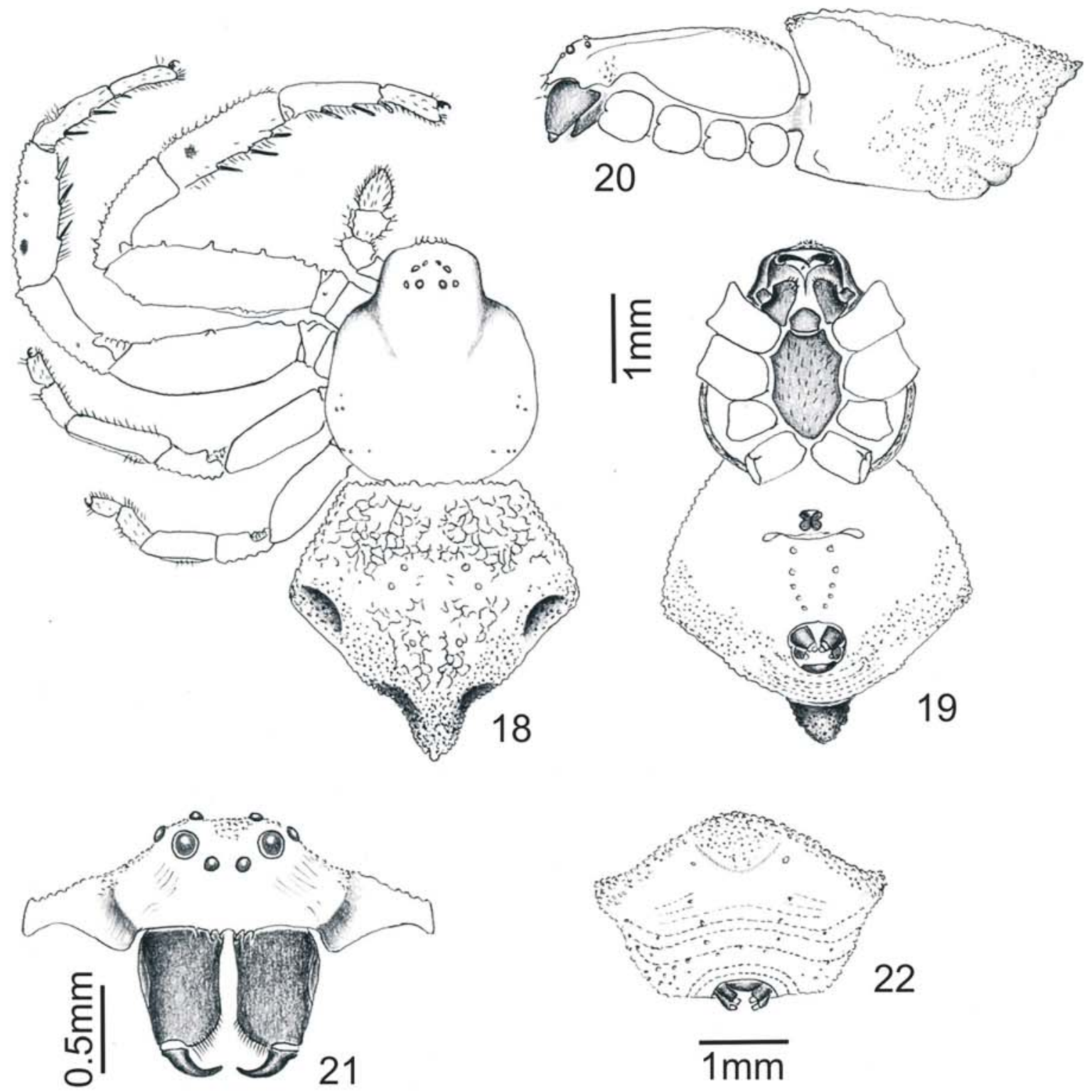

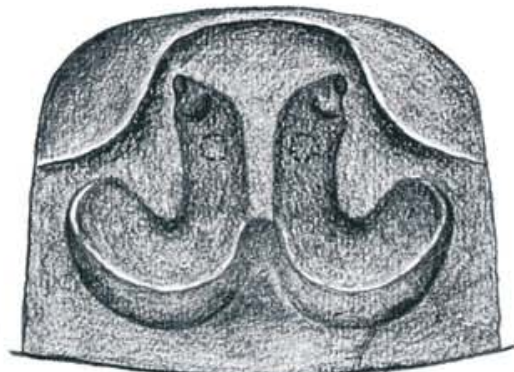

$0.25 \mathrm{~mm}$
23
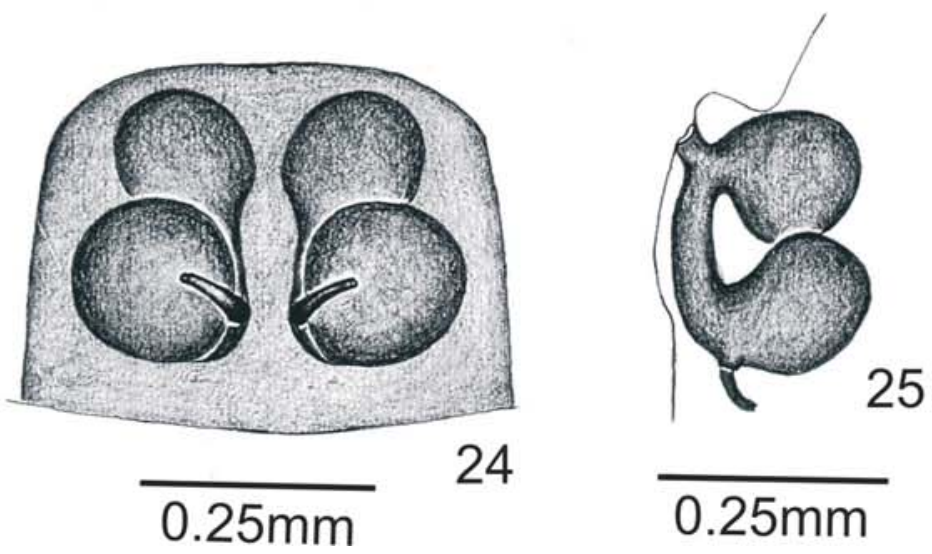

Figs.18- 25. Rejanellus pallescens (Bryant, 1940), female: 18, dorsal; 19, ventral; 20, lateral; 21, carapace and chelicerae, frontal view; 22, abdomen, posterior view; 23-25, epigynum: 23, ventral; 24, dorsal; 25, lateral. 

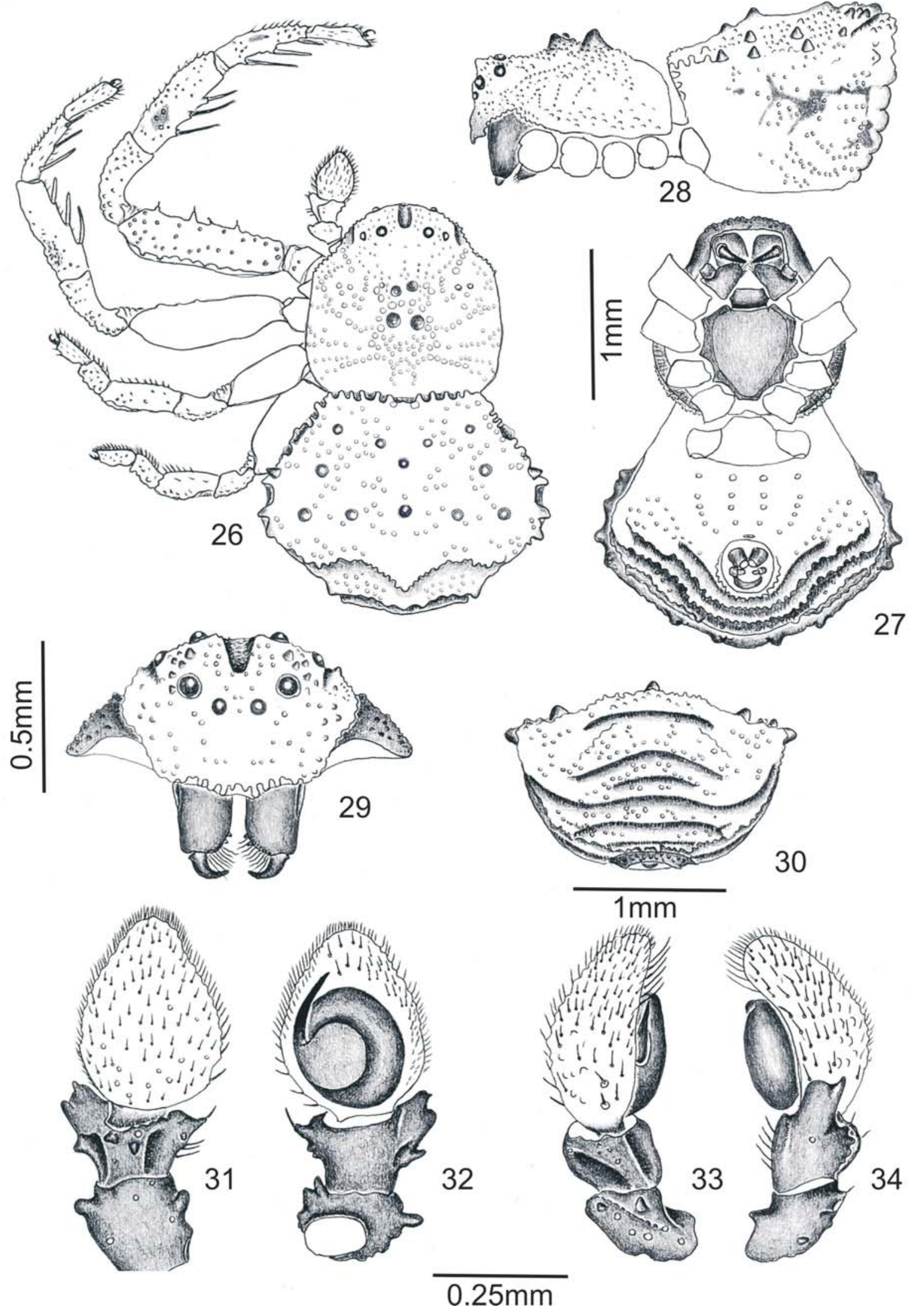

27

Figs. 26-34. Rejanellus pallescens (Bryant, 1940), male: 26, dorsal; 27, ventral; 28, lateral; 29, carapace and chelicerae, frontal view; 30 , abdomen, posterior view; 31-34, palpus: 31, dorsal; 32, ventral; 33, prolateral; 34, retrolateral. 
Dorsum of metatarsus III keeled, with five trichobothria; IV tuberculated and granulouse with four trichobothria. Tarsus III with three dorsal trichobothria, IV with two. Tubercles of the keels of patella, tibiae and metatarsus of all legs with chaetae.

Measurements. Leg I: femur 3.40, patella 2.00, tibia 2.15, metatarsus 1.55 , tarsus 0.95 , total 10.05 ; II: $3.15 / 1.90$ / 2.10/1.50/0.95/9.60; III: 2.00/1.05/1.50/0.65/0.50/5.70; IV: 1.75/0.85/1.25/0.65/0.45/4.95.

Palpus: femur 0.75 long, 0.30 wide; patella 0.50 long, 0.50 wide; tibia 0.50 long, 0.65 wide, at apex, with two excavations, each one with three trichobothria, one dorsal basal and another middle ectal; tarsus 0.70 long, 0.50 wide, with one conspicuous apical claw.

Abdomen: pentagonal, 4.40 long, 4.50 wide, 2.85 high, whitish yellow, strongly reticulated of white, with three black spots, one each side, behind the posterior lateral angles and another one at the apex of the posterior tubercle, this one less conspicuous. Laterals whitish yellow as on the dorsum, venter light yellow. Tegument poorly sclerotized. Dorsum and laterals microgranular. Dorsum with four central circular depressions and two more on the posterior third. Ventral face not granular. Anterior margin with large tubercles intercalated by shorter ones, lateral ones also tuberculated and the posterior, only close to the tubercle. Spinnerets light yellow. Epigynum anteriorly prominent (fig. 23) with fecundation openings very small, laterally disposed.

Male: total length 2.75. Carapace 1.32 long, 1.32 wide, high including the hump 0.67 , reddish-brown; cephalic region lighter; top of tubercles and granules milky-yellow. Dorsum convex and high. Cephalic region less pronounced than in the female, proportionally wider and rounded. Lateral margins almost parallel. Tegument strongly sclerotized, granular and tuberculous. The four median dorsal tubercles that form the hump very developed. Granules linearly disposed, delimiting the thoracic radial striae (fig. 18). Chelicerae of the same color of the carapace, 0.26 long, 0.22 wide with three small teeth on the promargin, retromargin with two. Sternum scutiform (fig. 27), as wide as long, 0.62, same color of the carapace. Endites 0.32 long, 0.15 wide, light chestnut, and convergent. Labium 0.17 long, 0.25 wide, same color of coxae. Clypeus 0.30 high, almost vertical, median portion protruded forward, margin with longitudinal protuberances alternated by depressions (fig. 29).

Eye diameters and eye interdistances: AME 0.06, ALE 0.10, PME 0.07, PLE 0.07, AME-AME 0.07, AMEALE 0.06, PME-PME 0.21, PME-PLE 0.06. MOQ length frontal view 0.30 , dorsal view 0.25 , anterior wide 0.21 , posterior wide 0.35 . Anterior row recurved posteriorly almost straight (figs. 26, 29).

Legs: formula 1234. Leg I: same color of carapace with tubercles and granules whitish. Femur with two tubercles on the proventral margin and three, less conspicuous, on the prodorsal margin, all of them intercalated by granules. Patella, prolateral and retrolateral faces almost smooth, microgranular. Tibia and metatarsus with 2.2 .2 ventral spines. Number and position of trichobothria, on tibia and metatarsus, as in female. Tegument granular as the dorsum of carapace. Leg II similar to I but with femur less tuberculous and less granular. Legs III and IV, same color of the anterior ones. Tibiae with many ventral curved chaetae directed to the top, these more abundant and thicker on ventral face of metatarsi and tarsi. Tegument granular as on anterior legs.

Measurements. I: femur 1.12 , patella 0.62 , tibia 0.75 , metatarsus 0.60, tarsus 0.35, total 3.45; II: 1.02/0.50/0.70/ 0.47/0.37/3.07; III: 0.62/0.32/0.48/0.22/0.200/1.85; IV: 0.56/ 0.32/0.42/0.22/0.22/1.84.

Palpus: femur 0.28 long, 0.12 wide; patella 0.20 long, 0.18 wide; tibia 0.12 long, 0.20 wide with a short retrolateral apophysis with dorsal prominence; cymbium convex with some low dorsal tubercles, irregularly distributed. Embolus curved, emerging on the middle of the prolateral margin of tegulum.

Abdomen pentagonal, convex, higher on center from where emerge two tubercles, bigger than the other ones, 1.50 long, 1.95 wide, 1.32 high, on level of the tubercles. Dorsum whitish yellow shadowed and spotted with brown and black. The dark shading do not cover all the dorsal surface, this with three white spots, one on each side of the posterior lateral tubercles and the third one, triangular, on the posterior third (fig. 26). Laterals as dorsum. Venter dark-yellow with four pairs of circular brown spots longitudinally disposed (fig. 27). Epigastric plates conspicuous, same color of coxae and sternum. Tegument well-sclerotized, densely tuberculous and granular. Anterior and lateral margins of dorsum sculptured (fig. 26). Spinnerets same color of venter, encircled by a chitinose half-ring, covered on its posterior half by whitish granules.

Geographic distribution. Cuba, Pico Turquino and Sierra de Trinidad; Haiti, Port-au-Prince.

Material examined. CUBA: South side of Pico Turquino, (300-500 feet), \&, VI.1936, P. J. Darlington col. (MCZ); Trinidad montains, Mina Carlota, \&, 23.VII.1947, Nutting col. (MCZ); HAITI: Hills near Port-au-Prince, (2000 feet), ơ, 2.X.1934, P. J. Darlington col. (MCZ).

\section{Rejanellus granulatus (Bryant, 1940) comb. nov.} (Figs. 35-43)

Onocolus granulata [sic] BRYANT, 1940:409, figs. 186,187, male holotype, original designation, Sierra de Cobre, Cuba, 0307.VII.1936, P. J. Darlington col., in MCZ (examined). RoEWER, 1954:757.

Diagnosis. The male is similar to the ones of $R$. pallescens and $R$. mutchleri in the shape of the abdomen but can be distinguished from these by the club shape of the retrolateral tibial apophysis, by the long and curved embolus with a wide basis (figs. 39, 41, 43).

Male: total length 2.50. Carapace 1.25 long, 1.22 wide, 0.55 high, at the tubercles level, dark brown, the smooth areas among the tubercles lighter, these ones darker; dorsum very convex with four conspicuous central tubercles. Cephalic region wide, narrower in front; tegument hardly chitinized, very granular and tuberculous; granules linearly disposed delimiting the thoracic radial furrows (fig. 35). Chelicerae same color of carapace, 0.21 long, 0.21 wide. Anterior face concave. Sternum scutiform, 0.60 long, 0.55 wide, fulvous, anterior 

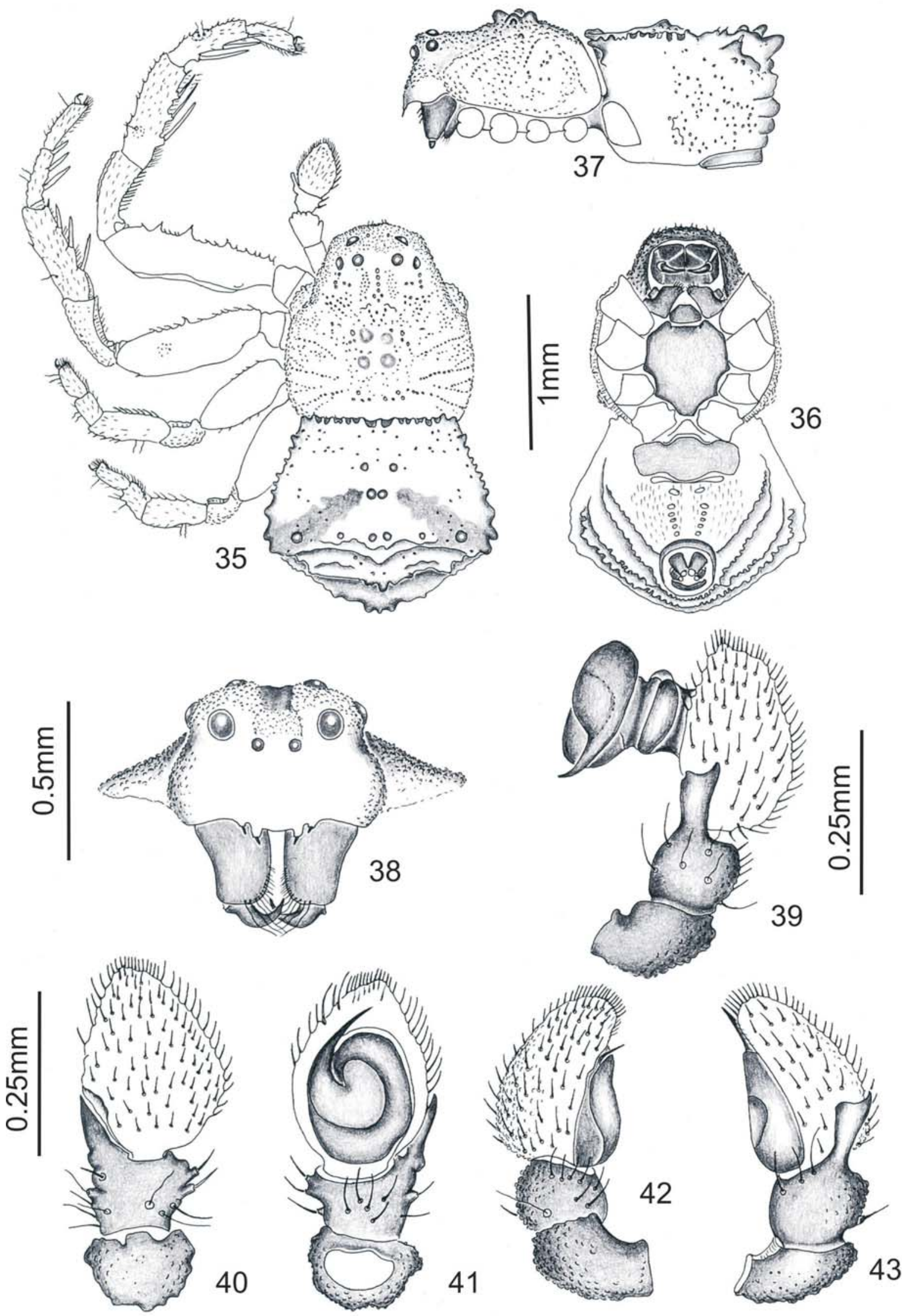

Figs. 35-43. Rejanellus granulatus (Bryant, 1940), male: 35, dorsal; 36, ventral; 37, lateral; 38, carapace and chelicerae, frontal view; 39-43, palpus: 39 , retrolateral, expanded; 40, dorsal; 41, ventral; 42, prolateral; 43, retrolateral. 
portion excavated, margins clipped at the coxae level, apex straight cut. Endites 0.30 long, 0.15 wide, at the apical third, convergent, of same color of sternum. Labium fulvous, 0.13 long, 0.23 wide (fig. 36). Clypeus 0.26 height, slightly proclivous, transversally convex, excavated below anterior eyes, granular, more protruded on the middle. Anterior margin with four conspicuous setiferous tubercles.

Eye diameters and eye interdistances: AME 0.05, ALE 0.10, PME 0.07, PLE 0.07, AME-AME 0.06, AMEALE 0.04, MPE-PME 0.18, PME-PLE 0.06, MOQ length, frontal view 0.28 , dorsal view 0.18 , anterior wide 0.16 , posterior wide 0.33 . Anterior row of eyes strongly recurved, posterior almost straight.

Legs: formula 1243. Leg I: all articles brown, tarsus fulvous. Femur with three conspicuous proventral setiferous tubercles intercalated by smaller ones, all of them with very short setae. Prolateral and retrolateral faces of patella almost smooth, microgranular, dorsum keeled and granular. Tibia with 2.2.2 long ventral spines intercalated by long hairs and one dorsal macroseta. Prolateral face granular with an excavation from which arise trichobothria. Dorsum granular and microsetaceous. Metatarsus with 2.2.2 long ventral spines, the apical shorter and curved at the top, hairy, claw tuff of simple hairs. Leg II: femur with one median proventral tubercule and one, each side of this, shorter, same color of I but femur not shadowed of black. Legs III and IV without tuberculi and spines, hairy. Tibia, metatarsus and tarsus with dorsal almost circular excavations from which arise trichobothria. Leg III fulvous lightly shadowed with brown on dorsal face, IV somewhat darker.

Measurements. Leg I: femur 1.10, patella 0.55, tibia 0.70 , metatarsus 0.52 , tarsus 0.35 , total 3.22 ; II: $0.97 / 0.50 /$ 0.62/0.42/0.35/2.87; III: 0.60/0.25/0.42/0.22/0.22/1.72; IV: $0.62 / 0.30 / 0.47 / 0.25 / 0.22 / 1.87$.

Palpus same color of carapace. Femur 0.32 long, 0.12 wide, patella 0.22 long, 0.20 wide, tibia 0.12 long, 0.17 wide. Tibia with long retrolateral tibial apophysis, few prolateral and retrolateral setiferous tubercles and some trichobothria on all faces except ventral. Embolus arising from the middle of the promargin of tegulum (fig. 41).

Abdomen pentagonal (fig. 35), more elevated on the center where occurs one pair of tubercles more conspicuous than the other, 1.25 long, 1.52 wide, 0.95 height, including the tubercles, without them, 0.70 . Dorsum whitish yellow with a triangular almost black spot. Color of laterals similar of dorsum, shadowed with dark brown. Venter yellow with a longitudinal row of six pairs of dark yellow circular depressions.

Geographic distribution: Cuba, Sierra de Cobre.

Material examined: Holotype only.

\section{Rejanellus mutchleri (Petrunkewitch, 1930) comb. nov. \\ (Figs. 44-62)}

Epicadus mutchleri Petrunkewitch, 1930:48, figs. 41-45, male holotype and female paratype, original designation, Jayua road, Adjuntas, Puerto Rico, 02.VI.1915, Mutchler col., in AMNH (examined); RoEwER, 1954:775; BonNeT, 1956:1713.
Observation. On the types label the collecting date is 08-13.VI.1915.

Conditions: missing right palpus, right leg II, left legs III, all detached, except IV left one.

Diagnosis. The short and almost horizontal tibial retrolateral apophysis are diagnostic to the male (figs. $49,52)$, the excavated epigynal atrium is for the female (figs. 60, 62).

Male: total length 2.57. Carapace 1.37 long, 1.30 wide, 0.57 height, at the hump level; dorsum strongly convex, much higher on the center forming a hump by the tubercles. Margins rounded, granular in front. Cephalic region not well-delimited, much prominent (fig. 44), ocular area elevated on the back (fig. 48). Tegument hardly chitinized, densely granular and tuberculous, granules disposed on more or less regular rows, microgranular areas among them (figs. 44, 46). Color in alcohol fulvous becoming dark brown, almost black, on the points of more concentration of tubercles and granules. Chelicerae short, same color of carapace, 0.18 long, 0.21 wide. Promargin and retromargin of the cheliceral furrow with two small teeth. Sternum scutiform, light brown, 0.62 long, 0.56 wider between coxae II and III, excavated on the anterior region, margins clipped, apex straight, with hairs on the lateral margins (fig. 45). Endites dark fulvous, 0.31 long, 0.15 wide, convergent, apical region rounded and scopulated (fig. 45). Labium, same color of sternum and endites, 0.15 long, 0.25 wide. Clypeus proclivous, 0.31 high, anterior margin prominent, festooned, projecting over the chelicerae with wrinkled surface, tuberculous and microgranular.

Eye diameters and eye interdistances: AME 0.05, ALE 0.11, PME 0.08, PLE 0.08, AME-AME 0.06, AMEALE 0.06, PME-PME 0.21, PME-PLE 0.07. MOQ length 0.28 frontal view, 0.20 dorsal view, anterior width 0.17 , posterior width 0.37 . Anterior eyes row strongly recurved, posterior straight.

Legs: formula 1234. Leg I same color of carapace. Femur with a row of tubercles on both, proventral and prodorsal margins, the prodorsal ones less numerous, all bearing a spine-like setae. Prolateral, retrolateral and dorsal surfaces smooth. Dorsum of patella tuberculous and granular. Tubercles and granules are linearly disposed and form three keels, one median and two lateral. Tibia with 2.2.2 ventral spines. On the basal third of the prolateral face, there is an excavation from which arise three trichobothria. Dorsal face keeled with only two trichobothria. Tegument tuberculous, granular with very short chaetae. Metatarsus with 2.2.2 ventral spines that decrease in length from base to apex. Dorsal face carinated with a submedian excavated area from which arise two trichobothria. Tarsus more dilated at the apex with one dorsal trichobothrium. Claws with only one tooth. Leg II as I but the femur less tuberculous. Legs III and IV as the anterior ones but the femur are not tuberculous.

Measurements. Leg. I: femur 1.12, patella 0.61, tibia 0.75 , metatarsus 0.57 , tarsus 3.75 , total 3.43 ; II: $1.00 / 0,56 /$ 0,68/0.50/0.37/3.12; III: 0.68/0.37/0.50/0.31/0.22/2.09; IV: $0.68 / 0.32 / 0.46 / 0.12 / 0.22 / 2.01$. 

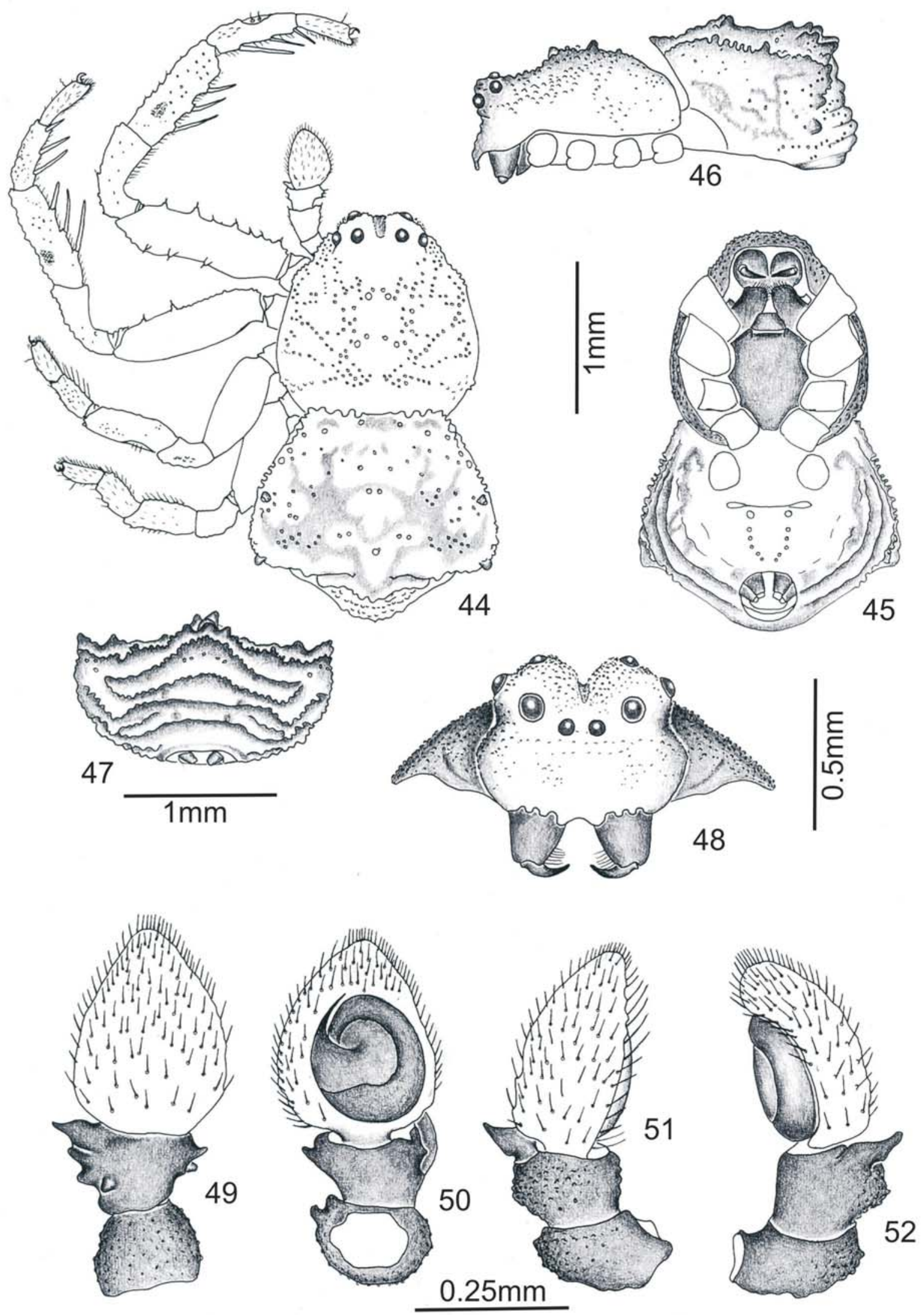

Figs. 44-52. Rejanellus mutchleri (Petrunkevitch, 1930), male: 44, dorsal; 45, ventral; 46, lateral; 47, abdomen, posterior view; 48, carapace and chelicerae, frontal view; 49-52, palpus: 49, dorsal; 50, ventral; 51, prolateral; 52, retrolateral. 


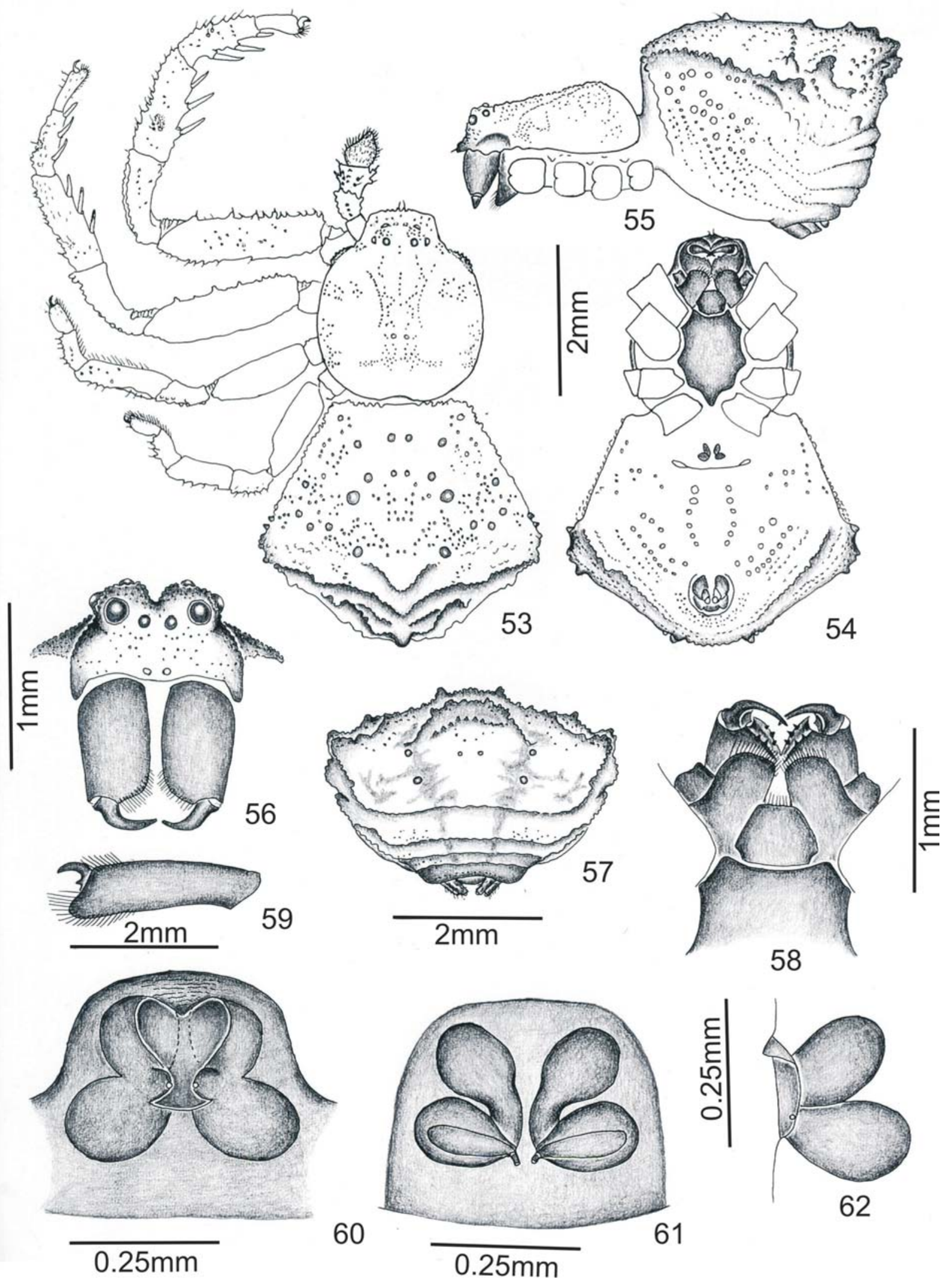

Figs. 53-62. Rejanellus mutchleri (Petrunkevitch, 1930), female: 53, dorsal; 54, ventral; 55, lateral; 56, carapace and chelicerae, frontal view; 57, abdomen, posterior view; 58, cefalotorax, ventral view; 59, tarsus II, retrolateral view; 60-62, epigynum: 60, ventral; 61, dorsal; 63, lateral. 

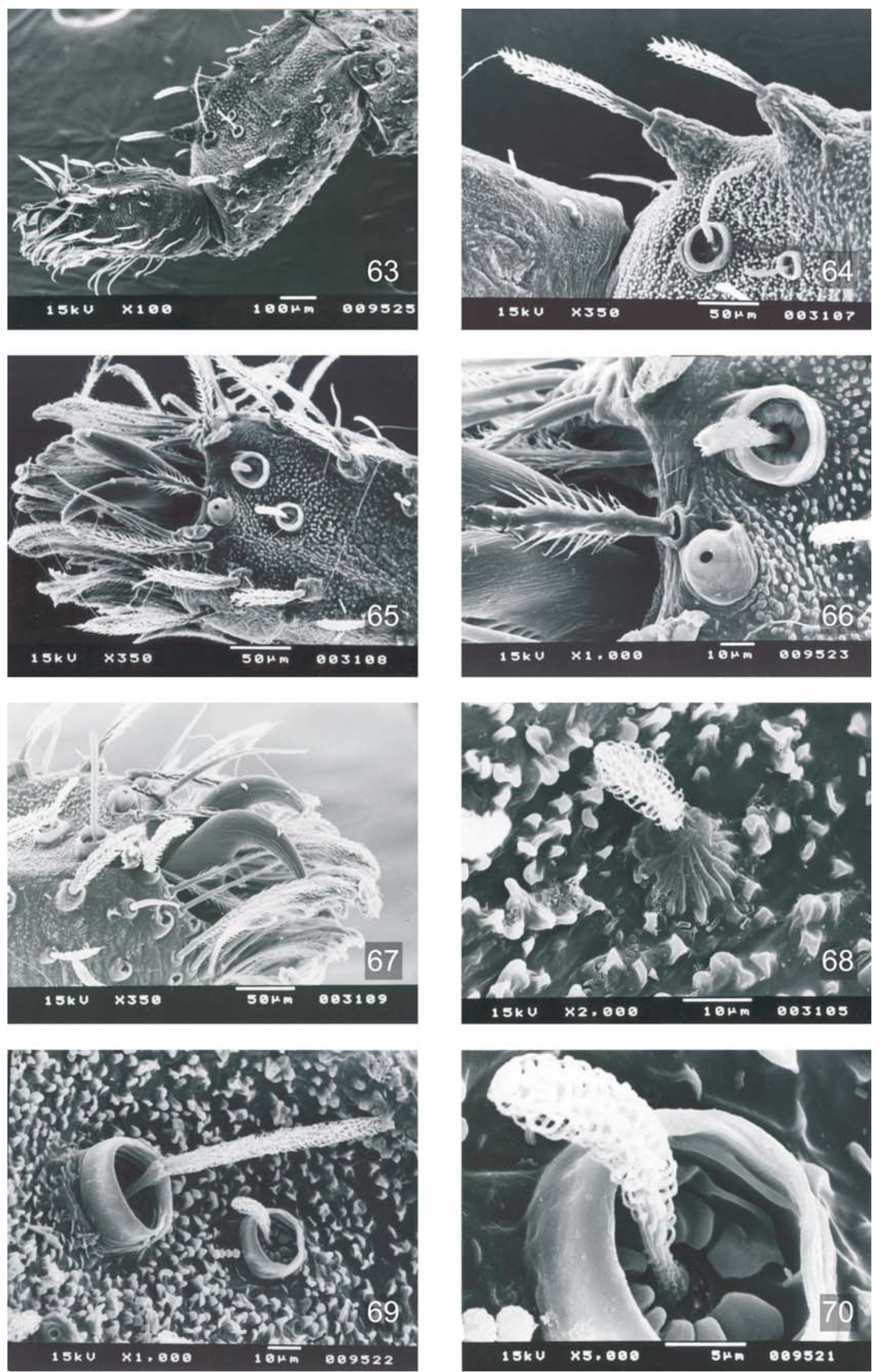

Figs. 63-70. Rejanellus venustus (Bryant, 1948): 63, leg metatarsus and tarsus I; 64, detail of metatarsus showing dorsolateral chaetae and trichobothriae; 65, tarsus I, dorsal; 66, detail of tarsus I showing the tarsal organ capsulate with circular aperture and its associate chaeta; 67, tarsus showing claws with single tooth; 68, detail of feathery chaeta on conic and sulcate basis; 69, long and short trichobothria; 70, detail of annular bothrium of short feathery trichobothria. 
Palpus: tibial retrolateral apophysis short and acuminate (figs. 49-52). Embolus short, base large, arising from the median portion of the prolateral margin of tegulum. Cymbium setaceous, patella and tibia granular.

Abdomen 1.27 long, 1.62 wide, 0.82 high. Pentagonal, higher on the center where there is a rounded longitudinal tuberculum and granular protuberance. Anterior margin festooned, laterals tuberculated. Top protruded, with many tubercles. Posterior declivity convex with rounded transverse crest resulted of the concentration of tubercles and granules, these linearly disposed (figs. 44, 47). Dorsum and laterals whitish yellow stained of black. Venter and epigastric plates fulvous. Spinnerets yellow encircled by a chitinous ring. Tubercles and granules white, fulvous and dark brown with no chaetae and hairs.

Female: total length 5.75. Carapace 2.30 long, 2.25 wide, 0.87 high. Dorsum less convex than in the male (fig. 55). Cephalic region well-delimited, lateral margins rounded, granular on the cephalic region. Ocular area more elevated than the remaining, forming a depression between the posterior eyes (fig. 56).Tegument hardly sclerotized, densely granulated (figs. 53,55 ). Color as in the male. Chelicerae: 0.65 long, 0.42 wide, light yellow stained of brown. Promargin of fang furrows with three teeth, retromargin with two (fig. 58). Sternum 1.12 long, 0.83 wide, light yellow, convex, and hirsute (fig. 54). Endites 0.55 long, 0.25 wide, yellow. Labium 0.32 long, 0.42 wide, yellow. Clypeus strongly procurved, 0.33 height, granular, with two strong median spine-like setae.

Eye diameters and eye interdistances: AME 0.06, ALE 0.15, PME0.12, PLE 0.12, AME-AME 0.07, AME-ALE0.06, PME-PME 0.25, PME-PLE 0.87. MOQ length 0.28, frontal view, dorsal view 0.32 , anterior width 0.20 , posterior width 0.60 . Anterior row strongly recurved, posterior straight, the anterior eye frontal, the posterior dorsal.

Legs: formula 1234. Leg I femur and patella as in the male. Tibia with 2.2.2 ventral spines, shorter than in the male. One prolateral basal chestnut excavation from which arise two trichobothria and one dorsal with only one. Metatarsus with 2.2.2 ventral spines, one prodorsal excavation with two trichobothria. Tarsus more dilated at top, claw with a single tooth (fig. 59). All articles, except tarsus, subquadrate on transversal section, tegument covered by granuli and tuberculi, these more conspicuous on patellae, tibiae and metatarsi. Leg II like I. Legs III and IV: femur smooth, patella dorsally granulouse, tibiae with one chestnut dorsal basal excavation from which arise three trichobothria, dorsum granular, venter with some chaete. Metatarsi with two dorsal trichobothria on the apical third, dorsum granular. Tarsi as in the anterior legs. Legs color as in male, tibiae IV darker than the other ones.

Measurements. Leg. I: femur 2.25, patella 1.30, tibia 1.45 , metatarsus 1.07 , tarsus 0.57 , total 6.65 ; II: $2.00 / 1.17 /$ 1.35/0.90/0.57/6.00; III: 1.37/0.75/1.02/0.67/0.42/4.25; IV: 1.32/0.65/0.82/0.52/0.35/3.67.

Abdomen 3.25 long, 3.50 wide, 2.75 high, at spinnerets level. Shape (fig. 57) as in male, white, shadowed of fuscous with many circular excavated yellowish fuscous areas. Distribution of granuli and tuberculi as in male. Spinnerets encircled by a sclerotized half-ring, open in front, less conspicuous than in the male. Epigastric plates not as conspicuous as in male. Spermatecae pear-shaped (figs. 60-62), fulvous.

Geographic distribution: Puerto Rico, Adjuntas and El Yunke, Sierra Luquillo.

Material examined. PUERTO RICO: Adjuntas ơ,, , VI.1915, Mutchler col.(AMNH F3964a); El Yunke, Sierra Luquillo, \&, 16-17.VII.1958, M. W. Sanderson col.(AMNH); o’, V.1938, Darlington col. (MCZ).

Acknowledgments. We are thankful to Laura Leibensperger (MCZ) and Norman I. Platnick (AMNH) for the loan of specimens.

\section{REFERENCES}

Bonnet, P. 1956. Bibliographia Araneorum. Analyse méthodique de toute la littérature aranéologique jusqu'en 1939. Toulouse, Douladoure. v.2, part2, p.9191925.

Bryant, E. B. 1940. Cuban spiders in the Museum of Comparative Zoology. Bulletin of the Museum of Comparative Zoology 86(7):247-554.

1948. The spiders of Hispaniola. Bulletin of the Museum of Comparative Zoology 100(4):331-459.

Lise, A. A. 1981. Tomisídeos neotropicais V: Revisão do gênero Onocolus Simon, 1895 (Araneae, Thomisidae, Stephanopsinae). Iheringia, Série Zoologia (57):3-97.

Petrunkevitch, A. 1930. The spiders of Porto Rico. Transactions of the Connecticut Academy of Arts and Sciences 31:1191.

Platnick, N. I. \& Shadab, M. U. 1975. A revision of the spider genus Gnaphosa (Araneae, Gnaphosidae) in America. Bulletin of the American Museum of Natural History 155: $1-66$.

Pickard-Cambridge, O. 1871. Arachnida. Zoological Records 7:207-224.

Roewer, C. Fr. 1954. Katalog der Araneae von 1758 bis 1940. Bruxelles, Institut Royal des Sciences Naturelles de Belgique. 923p.

Simon, E. 1892-1895. Histoire Naturelle des Araigneés. 2ed. Paris, Librairie Encyclopédique de Roret. v.1, 1084p.

Recebido em novembro de 2004. Aceito em abril de 2005. ISSN 0073-4721

Artigo disponível em: www.scielo.br/isz 